\title{
Tense marking in children with autism
}

\author{
JENNY A. ROBERTS \\ Temple University \\ MABEL L. RICE \\ University of Kansas \\ HELEN TAGER-FLUSBERG \\ Boston University School of Medicine
}

\begin{abstract}
ADDRESS FOR CORRESPONDENCE
Helen Tager-Flusberg, PhD, Lab of Developmental Cognitive Neuroscience, Department of Anatomy \& Neurobiology, Boston University School of Medicine, 715 Albany Street, L-814, Boston, MA 02118-2526. E-mail: htagerf@bu.edu
\end{abstract}

\begin{abstract}
A recent large-scale study identified a subgroup of children with autism who had a language profile similar to that found among children with specific language impairment (SLI), including difficulties with nonsense word repetition, an ability that has been implicated as one clinical marker for SLI. A second clinical marker for English-speaking children with SLI is high rates of omission of grammatical morphemes that mark tense in obligatory contexts. This study used experimental probes designed to elicit third person and past tense morphology with a large heterogeneous sample of children with autism. The subgroup of children with autism who were language impaired showed high rates of omission of tense marking on the experimental tasks. In addition, some of the children with autism made performance errors that were specific to the autistic population, such as echolalia. These findings further refine the characteristics of language impairment found in a subgroup of children with autism.
\end{abstract}

Autism is a complex neurodevelopmental disorder that is defined on the basis of symptoms in three behavioral domains: problems in social interaction, problems in communication, and restricted repetitive and stereotyped patterns of interests and activities (American Psychiatric Association [APA], 1994). Within the domain of communication, diagnostic features include delays and deficits in language acquisition, as well as qualitative impairments in discourse and other pragmatic aspects of language. The major emphasis in research on language in autism has focused on the pragmatic impairments, which are viewed as universal among individuals on the autism spectrum and are specific to this disorder (Lord \& Paul, 1997; TagerFlusberg, 1999). The pragmatic language impairments noted in autism include a restricted range and less frequent use of communicative functions (Landry \& Loveland, 1989; Stone \& Caro-Martinez, 1990; Wetherby, Prizant, \& Hutchinson, 1998; Wetherby \& Prutting, 1984), difficulties with rules of discourse, such as maintaining ongoing topics of conversation, observing rules of taking turns, providing new information, or following a partner's conversational topic 
(Loveland, McEvoy, Tunali, \& Kelley, 1990; Tager-Flusberg, 1997; TagerFlusberg \& Anderson, 1991). Other difficulties include use of echolalia (TagerFlusberg \& Calkins, 1990) and difficulties with deixis (Lee, Hobson, \& Chiat, 1994; Tager-Flusberg, 1994).

There has been less emphasis on studies exploring the language deficits in autism, primarily because in earlier studies that investigated the acquisition of phonology, syntax, and morphology, children with autism were no different from age-, IQ-, or language-matched comparison groups (e.g., Bartolucci \& Albers, 1974; Bartolucci \& Pierce, 1977; Bartolucci, Pierce, Streiner, \& Eppel, 1976; Pierce \& Bartoclucci, 1977; Tager-Flusberg, Calkins, Nolin, Baumberger, Anderson, \& Chadwick-Dias, 1990). Nevertheless, it is well known that there is significant heterogeneity among children with autism in the onset of language and rate of development. Until recently this heterogeneity has not been incorporated into investigations of language skills in autism, thus potentially obscuring important aspects of language disorder in this population.

A recent large-scale study of children with autism investigated the nature of language impairments among verbal children with autism, with particular interest in defining the phenotypes of different subgroups. Kjelgaard and Tager-Flusberg (2001) tested children with autism on a battery of standardized language tests tapping articulation, vocabulary, and higher order syntactic and semantic skills. Based on a review of standard scores, they identified subgroups of children. Some children with autism were found to have normal language skills on all the standardized tests, whereas others performed significantly below chronological age expectations. The profile of performance across the standardized measures for the language-impaired children with autism was similar to the profile that has been found among children with specific language impairment (SLI) as reported by Tomblin and Zhang (1999). This profile included relatively spared articulation skills, moderate impairments in vocabulary, and more profound deficits in the use of higher order semantic and syntactic knowledge. Kjelgaard and Tager-Flusberg (2001) included a nonword repetition measure in their battery of standardized language measures. Even the children with autism who did not have mental retardation but were language impaired performed poorly on this test. Because nonword repetition is considered an important clinical marker for SLI (Bishop, North, \& Donlan, 1996; Conti-Ramsden, Botting, \& Faragher, 2001; Dollaghan \& Campbell, 1998; Gathercole \& Baddeley, 1990; Tager-Flusberg, \& Cooper, 1999), these findings were taken as evidence that the language phenotype of this subgroup of children is similar to the phenotype for SLI.

A number of older studies of English-speaking children with autism investigated grammatical morphology in obligatory contexts, based on data from spontaneous speech samples. These earlier studies must be interpreted with caution as they included very small numbers of children who varied widely in age, mental age, and language ability. Two cross-sectional studies found differences between children with autism and a comparison group of normal children or children with mental retardation in the mastery of certain grammatical morphemes (Bartolucci, Pierce, \& Streiner, 1980; Howlin, 1984). Bartolucci et al. (1980) found that omission of certain morphemes in obligatory contexts was more frequent among children with autism, particularly articles ( $a$, the), auxiliary and copula verbs, past tense, third person present tense, and present progressive. These findings were later replicated 
by Howlin (1984). In a longitudinal study, Tager-Flusberg (1989) also found that children with autism were significantly less likely to mark past tense than were matched controls with Down syndrome. One pilot study by Bartolucci and Albers (1974) compared children with autism to mentally retarded and normal controls in performance on a task designed to elicit production of present progressive -ing and past tense -ed for different verbs. The children with autism performed well on the present progressive form, as did the controls. They were, however, significantly impaired on the past tense elicitation trials. Across these studies then, marking tense, particularly past tense, was impaired among children with autism. However, Bartolucci et al. (1980) attributed these difficulties to semanticpragmatic deficits in handling deictic categories or shifting reference, rather than to deficits in morphosyntax.

Other researchers have also noted the similarities in language profiles among some children with autism and other groups of language impaired children (e.g., Rapin, 1996), including children with semantic-pragmatic disorder, now called pragmatic language impairment (cf. Bishop, Chan, Hartley, Adams, \& Weir, 2000; Bishop \& Rosenbloom, 1987; Conti-Ramsden, Crutchley, \& Botting, 1997; Rapin $\&$ Allen, 1983). Based on these similarities, Bishop (2000) has argued that there are no clear diagnostic boundaries between autism, pragmatic language impairment, and SLI; rather, these represent overlapping heterogeneous disorders that lie on a continuum.

The goal of the present study was to investigate further the phenotype of language disorder among children with autism, with a specific focus on testing the potential parallels between language impaired children with autism and SLI. In addition to deficits in nonword repetition, tense-marking has been identified as another clinical marker for SLI in English-speaking children (Rice \& Wexler, 1996; Rice, Wexler, \& Cleave, 1995; Rice, Wexler \& Hershberger, 1998; Rice, Wexler, Marquis \& Hershberger, 2000). Children with SLI have particular difficulty with grammatical morphemes that carry tense, including third-person singular present tense (e.g., $-s$ in sings) and past tense for both regular verbs (e.g., -ed in walked) and irregular verbs (e.g., went, fell). Children with SLI frequently omit these morphemes in everyday conversation (e.g., Leonard, Bortolini, Caselli, McGregor, \& Sabbadini, 1992; Rice \& Wexler, 1996) and fail to produce them when given experimental probes (Rice et al., 1995).

Our study reopens the question of whether a subgroup of children with autism show deficits in marking tense that are similar to those found among children with SLI. We used experimental tasks drawn from the literature on SLI, developed by Rice and her colleagues (Rice et al., 1995), analyzing both overall performance and error patterns among our participants. Our sample included a relatively large number of children who had participated in the study by Kjelgaard and Tager-Flusberg (2001) in the previous year. We included children with high and low IQ scores, thus representing the broad range that characterizes the autism spectrum. However, because research on SLI typically limits the definition of this disorder to children whose nonverbal IQ scores are in the normal range, we also subdivided our sample into those with normal IQ scores and those with mild/moderate mental retardation for some analyses. In this way, we could more directly compare our findings to those reported in the literature on SLI. 
Roberts et al.: Tense marking in autism

Table 1. Participant characteristics

\begin{tabular}{lcccccc}
\hline \hline Group & $N$ & Age (months) & PPVT & Full Scale IQ & Verbal IQ & Nonverbal IQ \\
\hline Normal & & & & & & \\
Mean & 27 & 103.6 & 101.6 & 92.2 & 92.1 & 95.0 \\
SD & & 30.2 & 17.1 & 18.8 & 18.6 & 21.0 \\
Range & & $61-185$ & $85-149$ & $59-141$ & $63-133$ & $53-153$ \\
Borderline & & & & & & \\
Mean & 16 & 105.7 & 76.2 & 73.7 & 74.0 & 79.6 \\
SD & & 30.8 & 5.0 & 13.1 & 11.0 & 18.7 \\
Range & & $72-160$ & $70-84$ & $57-105$ & $59-97$ & $49-114$ \\
Impaired & & & & & & \\
Mean & 19 & 117.4 & 54.6 & 62.5 & 60.3 & 71.3 \\
SD & & 24.1 & 8.9 & 13.5 & 10.1 & 17.0 \\
Range & $84-181$ & $40-68$ & $42-90$ & $51-89$ & $43-102$ \\
\hline \hline
\end{tabular}

\section{METHOD}

\section{Participants}

The study included 62 children with autism, drawn from a larger longitudinal study of language and social cognitive development in children with autism, all of whom had participated in Kjelgaard and Tager-Flusberg's (2001) study. The sample included 54 boys and 8 girls between the ages of 5 and 15 years and included all the children who remained in the larger study and were able to complete the experimental tasks described below. Children were diagnosed with autism using $D S M-I V$ criteria (APA, 1994). The diagnosis was based on the Autism Diagnostic Interview-Revised (Lord, Rutter, \& LeConteur, 1994) and the Autism Diagnostic Observation Schedule (Lord et al., 2000) and confirmed by an expert clinician.

Participants were divided into three groups on the basis of their performance on the Peabody Picture Vocabulary Test III (PPVT; Dunn \& Dunn, 1997), using the criteria that Kjelgaard and Tager-Flusberg (2001) adopted for defining language subgroups in autism. Group 1 (Normal) included children whose PPVT standard scores were 85 or above, within the normal range $(n=27 ; 21$ of these children had nonverbal IQ [NVIQ] scores 85 or higher); group 2 (Borderline) included children whose PPVT standard scores were between 70 and 84 , or between 1 and 2 standard deviations below the mean ( $n=16 ; 7$ of these children had NVIQ scores of 85 or higher); and group 3 (Impaired) included children whose PPVT standard scores were below 70, two or more standard deviations below the mean $(n=19 ; 4$ of these children had NVIQ scores of 85 or higher). There were no significant age differences between these three groups, $F(2,59)=1.38, n s$. Table 1 presents the descriptive characteristics of the participants in these three subgroups.

\section{Procedures}

Standardized measures. Children were administered a battery of standardized tests to assess their general cognitive and language abilities. 
COGNITIVE ABILITY. IQ was assessed using the Differential Abilities Scales (DAS; Elliott, 1990). Either the preschool or school age version of the DAS was administered, depending on the children's age and ability level. The DAS yielded a full scale IQ (FIQ), verbal IQ, and NVIQ subscores for all children tested within age level. Three children in the current sample were not tested within age level so only FIQ scores were available for them.

LANGUAGE. Two standardized language tests were administered, including the PPVT, and the Repetition of Nonsense Words (NWRT; Korkman, Kirk, \& Kemp, 1998). The NWRT is a subtest from the NEPSY, a comprehensive developmental neuropsychological assessment battery. Standard scores for the NWRT were not available for four participants, who did not fit the age range specified for this test. The language tests were administered and scored by a speech-language pathologist (CFY or CCC-SLP), and the NWRT was administered by audiotape. A second coder checked all test data.

ARTICULATION OF WORD FINAL CONSONANTS. Tense-marking errors or omissions may occur as the result of difficulties in the articulation of consonant sounds. In order to rule out this possibility, we examined the children's phonological production on the Goldman-Fristoe Test of Articulation (Goldman \& Fristoe, 1986). This led to the elimination of three children who omitted /s/ or /z/ phonemes from the analysis on third person singular tense. All the participants were able to produce $/ \mathrm{t} /$ or $/ \mathrm{d} /$ phonemes so they were all included in the analyses of performance on the past tense task.

Experimental tasks. Linguistic probes designed to elicit third-person singular and past tense forms (Rice et al., 1995) were presented to the children.

THIRD-PERSON SINGULAR. The third-person present tense $-s$ forms were elicited through pictures depicting various occupations, such as dentist and farmer. On an initial training example, children were told that a teacher does lots of things: goes to school, helps children, and teaches. They were then presented with 12 test trials in a fixed order and asked to tell the examiner what the person does in their occupation through questions such as, "What does a farmer do?" and directives such as, "Tell me what a dentist does."

PAST TENSE. Participants were given opportunities to produce 11 regular past tense -ed forms and 8 irregular past tense forms on lexical verbs such as wash, color, fall, and catch. There was an initial training example using the verb rake. The experimenter gave the following instructions: "I have two pictures. I will describe the first one, and you tell me about the second picture." After placing the first picture in front of the child, the experimenter said, "Here is the boy raking." Then the second picture was placed on the table, and the experimenter said: "Now he is done. Tell me what the boy did." If the child failed to produce the target verb, two prompts were given, including "Tell me what he did to the leaves" or "What happened? The boy ." If children did not produce the target raked, the 
Roberts et al.: Tense marking in autism

Table 2. Percentage of responses on third person singular probes

\begin{tabular}{|c|c|c|c|c|c|c|c|c|}
\hline Group & Correct & $\begin{array}{l}\text { Bare } \\
\text { Stem }\end{array}$ & $\begin{array}{l}\text { Other } \\
\text { Verb }\end{array}$ & $\begin{array}{c}\text { No } \\
\text { Response }\end{array}$ & $\begin{array}{l}\text { No } \\
\text { Verb }\end{array}$ & $\begin{array}{l}\text { Incorrect } \\
\text { Irregular }\end{array}$ & $\begin{array}{c}\text { Creative } \\
\text { Verb }\end{array}$ & $\begin{array}{l}\text { Over } \\
\text { Regular }\end{array}$ \\
\hline \multicolumn{9}{|l|}{ Normal } \\
\hline Mean & 76.3 & 14.1 & 8.9 & $<1$ & 1.1 & $<1$ & $<1$ & $<1$ \\
\hline$S D$ & 28.8 & 22.4 & 16.9 & 2.6 & 4.2 & 1.9 & 2.6 & 1.9 \\
\hline \multicolumn{9}{|l|}{ Borderline } \\
\hline Mean & 61.3 & 21.9 & 14.4 & 2.5 & 4.4 & $<1$ & $<1$ & $<1$ \\
\hline$S D$ & 32.2 & 17.2 & 20.3 & 5.7 & 8.1 & 2.5 & $<1$ & $<1$ \\
\hline \multicolumn{9}{|l|}{ Impaired } \\
\hline Mean & 36.8 & 21.9 & 23.2 & 11.6 & 6.3 & 4.7 & $<1$ & 1.1 \\
\hline$S D$ & 23.3 & 17.2 & 25.0 & 18.0 & 11.1 & 8.4 & $<1$ & 3.1 \\
\hline \multicolumn{9}{|l|}{ Total } \\
\hline Mean & 60.3 & 18.2 & 14.7 & 4.5 & 3.5 & 1.8 & $<1$ & $<1$ \\
\hline$S D$ & 32.5 & 21.6 & 21.0 & 11.4 & 8.1 & 5.3 & 1.7 & 2.1 \\
\hline
\end{tabular}

Note: All values are percentages.

experimenter modeled the correct answer on the training trial. The 19 test trials followed in a fixed order, which intermixed the regular and irregular verbs.

SCORING. The children's responses were coded by one primary coder and checked by a second coder. All intercoder differences were discussed until consensus was reached. Children's responses were scored as correct or incorrect. Incorrect responses were then scored with respect to the type of errors made. The scoring criteria differed from those reported by Rice et al. (1995) because of some differences in responses between the SLI and autistic populations. In their study of children with SLI, Rice et al. (1995) did not include responses on third-person probes that were correct irregular responses (e.g., says, does, has, is), incorrect irregular responses (e.g., do+, $3 r d$ person $-s=$ "dues"), and other verb forms (such as auxiliary marking, "does go" or present progressive -ing). ${ }^{1}$ Because these were frequent responses made by some of the children with autism in the present study, they were included for analysis. Another difference in scoring involved criteria for echolalic responses. The first lexical verb produced that was judged not to be an echolalic response was scored (echolalic responses were determined through a combination of previous echolalic responses and/or responses that immediately followed the wording of the probe, e.g., "He does farm," following the probe, "Tell me what a farmer does").

\section{RESULTS}

\section{Third-person singular}

Table 2 presents the means and standard deviations for the percentage of correct responses on third-person singular present tense probes. Across all three groups of 
Table 3. Third person singular verb probes: Correlations with PPVT, age, IQ, and nonsense word repetition scores

\begin{tabular}{lcccrc}
\hline \hline & PPVT & Age & Verbal IQ & NVIQ & NWRT \\
\hline Correct $(\%)$ & $.538^{* *}$ & $.289^{*}$ & $.639^{* *}$ & .251 & $.435^{* *}$ \\
Bare stem & -.102 & $-.259^{*}$ & $-.318^{*}$ & .014 & -.067 \\
Other verb & $-.335^{* *}$ & -.022 & $-.322^{*}$ & -.097 & -.068 \\
\hline \hline
\end{tabular}

$N=62 .{ }^{*} p<.05 .{ }^{* *} p<.01$.

children, more than half of the responses ( $60 \%$, or approximately 7 out of 12$)$ were correct. This included both correct regular and irregular forms of the verb, with the majority of these correct regular forms. Of the responses that were not correct, the main errors were bare stem (unmarked) forms, followed by other verb forms, mostly present progressive -ing forms, no responses, or echolalic responses. Other error types were quite rare, as shown in Table 2.

This pattern was found across the different language subgroups, though, as predicted, there was a significant difference between groups in the percentage of correct responses provided, $F(2,59)=10.9, p<.0001$. Children in the Impaired group made significantly fewer correct responses to third person singular probes than the Normal group, $t(44)=4.92, p<.0001$, and the Borderline group, $t(33)=2.5, p=.01$. Although children in the Normal group produced fewer bare stem errors than either Borderline or Impaired groups, these differences were not significant, $F(2,59)=0.88$.

There was a significant difference between the groups in the percentage of trials on which children failed to respond to probes or provided echolalic responses, $F(2,59)=6.3, p=.003$. Children in the Impaired group were significantly more likely than children in the Normal group to fail to respond to probes or to provide echolalic responses, $t(44)=3.09, p=.003$. They were also more likely to do so than children in the Borderline group, although this difference only approached significance, $t(33)=1.9, p=.06$. An overall analysis of variance also revealed a significant difference between groups in the proportion of incorrect irregular verb responses, $F(2,59)=4.85, p=.011$. Pairwise comparisons revealed Impaired $>$ Normal, $t(44)=2.68, p=.012$, and Impaired $>$ Borderline approaching significance, $t(33)=1.88, p=.069$.

Table 3 shows a correlation matrix for responses on the third-person task and other measures. Correct performance was significantly correlated with age, verbal IQ, PPVT, and the NWRT, but not with NVIQ scores.

\section{Past tense}

Table 4 presents the responses by the different language subgroups on the past tense task, collapsed across regular and irregular forms. Averaged across all the children more than half the responses were correct, and the most frequent error pattern was using a bare stem verb. Children in the Normal and Borderline groups performed similarly with respect to the proportion of correct responses, as well as in the 
Roberts et al.: Tense marking in autism

Table 4. Percentage of responses on past tense probes

\begin{tabular}{|c|c|c|c|c|c|c|c|c|}
\hline Group & Correct & $\begin{array}{l}\text { Bare } \\
\text { Stem }\end{array}$ & $\begin{array}{l}\text { Other } \\
\text { Verb }\end{array}$ & $\begin{array}{c}\text { Over } \\
\text { Regular }\end{array}$ & $\begin{array}{c}\text { No } \\
\text { Response }\end{array}$ & $\begin{array}{l}\text { No } \\
\text { Verb }\end{array}$ & $\begin{array}{l}\text { Over Over } \\
\text { Regular }\end{array}$ & $\begin{array}{c}\text { Creative } \\
\text { Verb }\end{array}$ \\
\hline \multicolumn{9}{|l|}{ Normal } \\
\hline Mean & 63.8 & 12.3 & 10.0 & 7.5 & 4.7 & $<1$ & 1.0 & $<1$ \\
\hline$S D$ & 29.2 & 16.3 & 14.5 & 11.3 & 14.3 & 3.0 & 4.4 & 1.0 \\
\hline \multicolumn{9}{|c|}{ Borderline } \\
\hline Mean & 58.2 & 12.2 & 12.5 & 6.9 & 1.6 & 7.2 & 1.3 & $<1$ \\
\hline$S D$ & 28.9 & 14.9 & 21.2 & 8.1 & 4.2 & 2.5 & 4.1 & $<1$ \\
\hline \multicolumn{9}{|l|}{ Impaired } \\
\hline Mean & 30.6 & 23.4 & 25.7 & 5.9 & 12.3 & 2.3 & $<1$ & $<1$ \\
\hline$S D$ & 26.5 & 16.6 & 32.6 & 6.9 & 18.9 & 5.1 & $<1$ & $<1$ \\
\hline \multicolumn{9}{|l|}{ Total } \\
\hline Mean & 52.2 & 15.7 & 15.4 & 6.8 & 6.2 & 2.8 & $<1$ & $<1$ \\
\hline$S D$ & 31.4 & 16.6 & 23.7 & 9.2 & 14.6 & 13.0 & 3.5 & $<1$ \\
\hline
\end{tabular}

Note: All values are percentages.

proportion of omissions and other verb responses. In contrast, the Impaired group provided significantly fewer correct responses than either of the other subgroups, $F(2,59)=8.13, p=.001$; pairwise contrasts found Normal $>$ Impaired, $t(44)=$ 3.93, $p<.000$; Borderline $>$ Impaired, $t(33)=2.94, p=.006$.

The proportion correct on the past tense marking was then investigated separately for the regular and irregular past tense test items. As shown in Figures 1 and 2, children were generally better on the regular forms. Again, the Impaired group performed significantly worse than the Normal group on regular forms, $t(44)=$ $3.58, p=.001$, and irregular forms, $t(44)=3.4, p=.001$. They were also worse than the Borderline group on regulars, $t(33)=2.56, p=.015$, and irregulars, $t(33)=2.89, p=.007$.

As shown in Table 4, the proportion of bare stem responses for the Impaired group, collapsed across regular and irregular forms, was about twice that of either the Normal group or the Borderline group. This difference was statistically significant, $F(2,59)=3.16, p=.05$, with pairwise comparisons showing Impaired $>$ Normal, $t(44)=2.25, p=.03$, and Impaired $>$ Borderline, $t(33)=2.08, p=.045$. When the proportion of past tense omissions on regular versus irregular verbs was examined separately, there was a significant difference in the proportion of past tense omissions made on irregular verbs, $F(2,59)=5.18$, $p=.008$, but not regular verbs, $F(2,59)=.697, n s$. Pairwise comparisons revealed that proportion of omissions on irregular verbs for the Impaired group exceeded those of both the Normal group, $t(44)=2.71, p=.009$, and the Borderline group, $t(33)=2.62, p=.013$.

The proportion of responses that were echolalic, or classified as "no responses" by children in the Impaired group was more than twice the level of children in either the Normal group or the Borderline group; although these group differences only approached significance, $F(2,59)=2.67, p=.077$. The same was found 


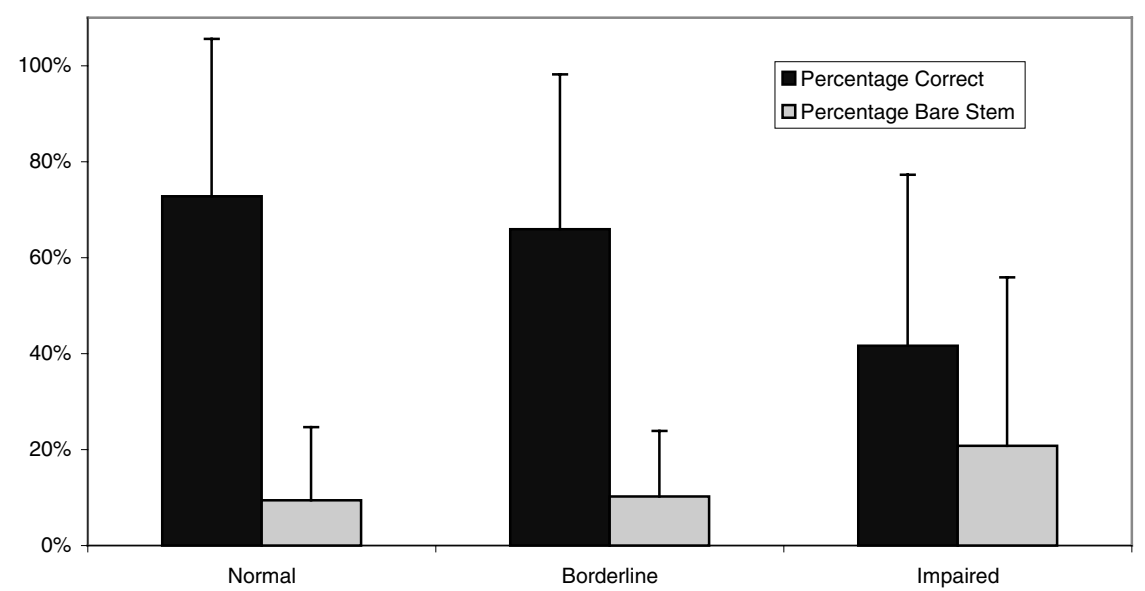

Figure 1. The proportion correct on past tense marking for regular past tense.

Irregular Past Tense

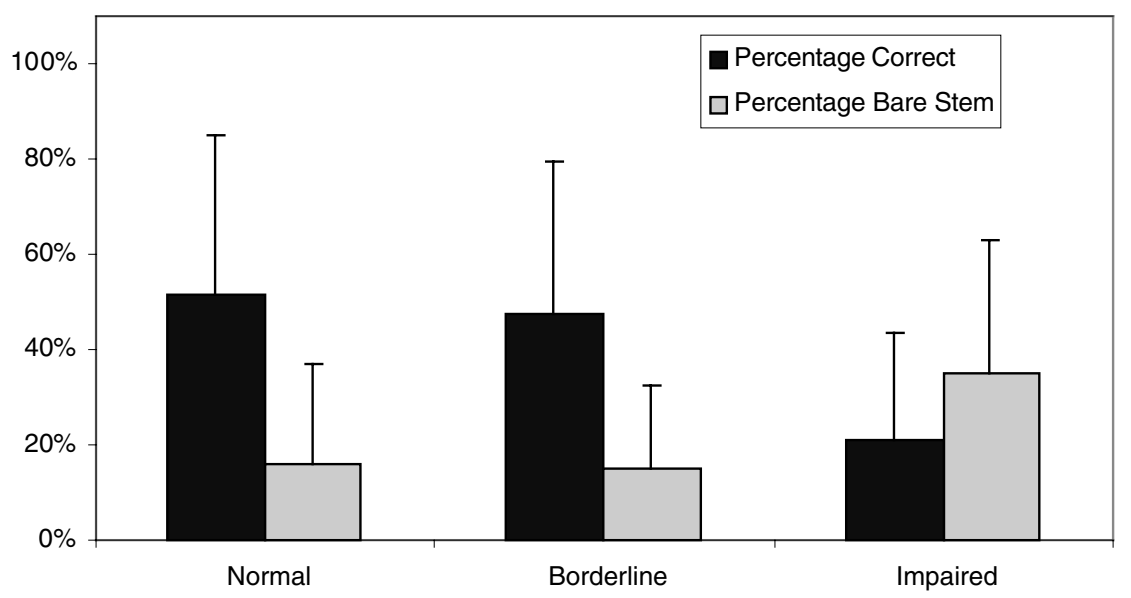

Figure 2. The proportion correct on past tense marking for irregular past tense.

for the proportion of responses that were classified as "other verb responses," $F(2,59)=2.76, p=.071$.

Table 5 shows the correlation matrix for past tense verb responses. Correct past tense responses were significantly correlated with age, verbal IQ, NVIQ, PPVT, and NWRT scores. Rice et al. (2000) found that for children with SLI, NVIQ predicted irregular past tense percent correct, but not regular past percent 
Roberts et al.: Tense marking in autism

Table 5. Past tense verb probes: Correlations with PPVT, age, IQ, and nonsense word repetition scores

\begin{tabular}{lccccr}
\hline \hline & PPVT & Age & Verbal IQ & NVIQ & NWRT \\
\hline Correct $(\%)$ & $.535^{* *}$ & $.308^{*}$ & $.583^{* *}$ & $.359^{* *}$ & $.509^{* *}$ \\
Bare stem & $-.281^{*}$ & -.093 & $-.386^{* *}$ & $-.309^{*}$ & $-.440^{* *}$ \\
Other verb & $-.329^{* *}$ & .027 & $-.269^{*}$ & -.077 & .034 \\
\hline \hline
\end{tabular}

$N=62 .{ }^{*} p<.05 .{ }^{* *} p<.01$

correct. In contrast, the present study on children with autism found that both regular and irregular past correct was correlated with NVIQ $(r=.35, p<.01$; $r=.31, p<.05$, respectively). Conti-Ramsden et al. (2001) also found modest correlations between NVIQ and a task to elicit past tense on both regular and irregular verbs.

Finally, the correlation between performance on the two experimental tasks tapping tense morphology was highly significant: $r=.79, p<.01$.

\section{Comparison with SLI children}

In order to allow us to compare our findings on children with autism to those reported for children with SLI, we reanalyzed our data using the same scoring criteria used by Rice et al. (1995), who had administered these tasks to children with SLI (average age of 5) and age- and mean length of utterance matched (average age of 3 ) normally developing controls. The following changes were made to the scoring criteria: (a) on both tasks, errors including other or creative verb, no verb, no response, and echolalic responses were excluded from the denominator; (b) on the third-person task, correct and incorrect irregular verbs were excluded.

Third person. Rice et al. (1995) found that normal 5-year-olds were correct on $95 \%$ of trials, normal 3-year-olds on 38\%, and the 5-year-old children with SLI on $26 \%$. At 8 years of age, the SLI group was at $96 \%$. Using the new scoring criteria, the children in the Normal group were correct on $81 \%$ of trials, the Borderline group on $69 \%$, and the Impaired group on $65 \%$ of trials. The language impaired children with autism (with a mean age of 8-9 years) performed somewhat better than 5-year-old children with SLI but worse than normally developing 5-year-olds and worse than SLI children in the same age range.

Past tense. On the regular past tense task, Rice et al.'s (1995) normal 5-yearolds were correct on $92 \%$ of attempts, the 3 -year-olds on $50 \%$, and the 5-yearold children with SLI only on $27 \%$. At 8 years of age, the SLI group was at 96\%. In our data, using the adjusted calculation, the Normal and Borderline groups both performed correctly on $86 \%$ of trials, whereas the Impaired group performed correctly on $68 \%$ of the trials. Again, the language impaired children with autism performed somewhat better than 5-year-old children with SLI but 


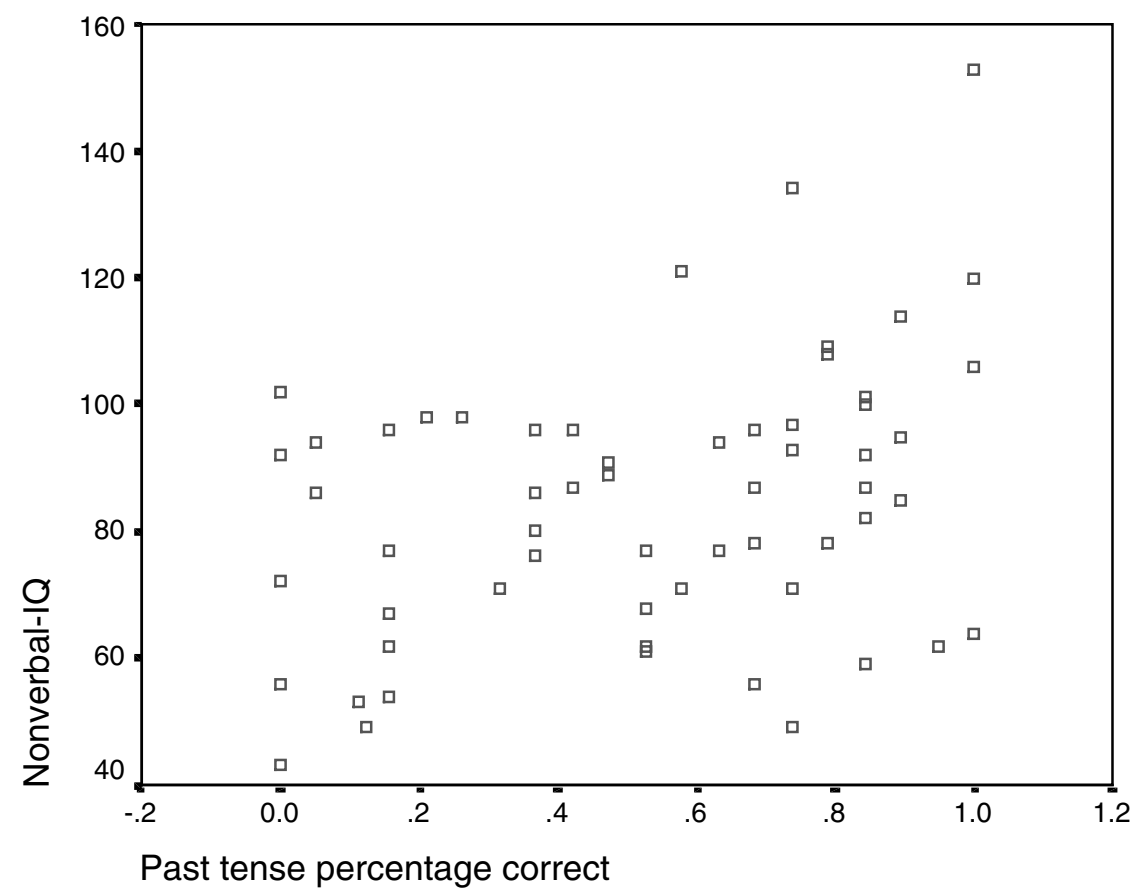

Figure 3. A scatterplot illustrating the relationship between nonverbal IQ and past tense percentage correct.

worse than normally developing 5-year-olds and SLI children in the same age range.

\section{The relationship between $I Q$ and tense marking}

Figure 3 presents a scatterplot illustrating the relationship between NVIQ scores and performance on the past tense task. This figure shows that there were some children with high NVIQ scores who performed poorly on the tense-marking task, whereas others with low IQ scores performed quite well. To better understand the role of IQ as a contributing factor in performance on tense marking, children were divided into two groups on the basis of their NVIQ scores. Following the traditional SLI literature (cf. Stark \& Tallal, 1981), normal IQ was defined as NVIQ scores of 85 and above $(n=32$, range $=85-153)$. Children with scores below 85 were defined as low NVIQ $(n=27$, range $=43-84)$.

Tense marking on both third person and past tense verbs was reexamined comparing children with normal or low NVIQ. On the third-person task there were no significant differences in the percentage of correct responses, $t(57)=0.93$; bare stem responses, $t(57)=.76$; overregularizations, $t(57)=.44$; responses without a verb, $t(57)=.75$, other verb types, $t(57)=.13$, or use of creative verbs, $t(57)=.12$. However, the low IQ children were significantly more likely 
to provide no response or to provide echolalic responses to third-person probes, $t(57)=2.05, p=.04$.

On the past tense probes, there was no significant difference between the two IQ groups in the percentage of correct responses, $t(57)=.15$; overregularizations, $t(57)=1.49$; responses without a verb, $t(57)=.52$; use of a different verb, $t(57)=.84$; creative verbs, $t(57)=.03$, or gave no response/echolalic response, $t(57)=1.46$. However, children with low IQs were significantly more likely to omit past tense marking on irregular past tense probes, $t(57)=2.03$, $p=.047$, and their general tendency to omit past tense markers on combined irregular and regular past tense verbs approached significance, $t(57)=1.935$, $p=.058$.

\section{Relationship between tense marking and nonsense word repetition}

Given that both tense marking and nonsense word repetition have been identified as important clinical markers for SLI, one might expect that these two markers would co-occur in children with autism showing an SLI profile. Performance on the NWRT was significantly correlated with the proportion of correct responses to the past tense $(r=.509, p<.01)$ and third-person singular probes $(r=.44$, $p<.01)$. This relationship between NWRT and tense marking may be mediated in part through general linguistic knowledge, as the correlations between NWRT and both past tense marking $(r=.39, p=.002)$ and third-person singular marking $(r=.3, p=.02$ ) diminished somewhat when PPVT scores were partialed out.

\section{DISCUSSION}

The goal of this study was to further refine the language phenotypes of verbal children with autism, with specific emphasis on identifying different subgroups within the population. We specifically examined whether language impaired children with autism show the same difficulties in marking tense as has been found among children with SLI. Our main findings were that the children with autism and language impairment showed high rates of omission on both the present and past tense experimental probe tasks. We also found some unique performance errors that reflected core autism deficits. In this discussion, we first examine the similarities and differences in the performance of language impaired children with autism and children with SLI on the experimental tasks tapping tense. We then consider the implications of these findings for considering the potential overlap between these populations.

\section{Tense marking in SLI and autism}

In the present study, we focused particularly on grammatical morphology because of its hypothesized significance in the SLI population (Bishop, 1992; Leonard, 1989; Leonard et al., 1992; Rice \& Wexler, 1996; Rice et al., 1995). Using the same elicitation tasks as Rice and her colleagues, we found deficits in tense marking for both third-person regular tense and past tense in the Impaired language subgroup of children. These deficits consisted primarily of null marking, or omissions of 
the markers being probed. This pattern of deficits mirrors the pattern reported in the SLI literature. When we scored the children's responses using Rice et al.'s (1995) criteria, the Impaired autism group performed somewhat better than the SLI children in their study; however, our children with autism were older (average 9 years old) than their SLI children (average age 5 years old). When compared to Rice's SLI longitudinal group at 8 years of age, the Impaired autism group showed a lower level of tense-marking, suggesting that the deficits may persist for a longer time in the Impaired autism group. These findings contrast somewhat with those from a recent study by Botting and Conti-Ramsden (2003), who compared agematched children with autism and children with SLI (average 10 years old), on a different past-tense probe task and found no differences between these groups. The differences may be attributable to differences in the grouping criteria across the two studies, although this remains as an open issue for further study.

Performance on the experimental tense tasks varied depending on subgroup status, which was defined on the basis of performance on standardized language measures. When performance on tense marking was compared across groups, children with autism in the Normal language group made the fewest errors and omissions, and children in the Impaired group made the most. However, despite these general group differences in language abilities, children with lower NVIQ scores were not significantly more likely to perform poorly on the tense marking tasks (see also Botting \& Conti-Ramsden, 2003). This suggests that the Impaired subgroup of children, who provided a significantly lower proportion of correct responses on both third-person singular and past tense regular and irregular verb probes, were not simply low performers across the board.

\section{Unique error patterns in children with autism}

In addition to the similarities in the patterns of performance on these experimental tasks between the Impaired children with autism and children with SLI, some unique performance errors were found among some of the children with autism. Although omissions were the most frequent error for both third-person singular and past tense verbs, other errors were noted. Some especially prevalent errors produced by the lowest functioning children included a tendency to repeat the stimulus probe (echolalic responses) or to perseverate on previous responses, both of which were counted as no response errors. These responses may reflect difficulties that the children had in understanding the instructions or nature of the task. Regardless of IQ level, many children with autism show difficulties with the task demands of formal testing (Tager-Flusberg, 2000).

In the present study, children in the Impaired group also made many "other verb" responses on third-person singular probes. These "other verb" responses typically involved providing present progressive -ing forms, as in the response, "He fixing the teeth," when asked what a dentist does, or contractible copula forms, as in the response, "He's a hero," when asked what a cowboy does. Many of the responses coded as "other verb," particularly in the Impaired group, were semantically inappropriate, off-topic responses. Responses coded as "other verb" on the past tense probes also involved a high proportion of present progressive -ing responses, such as the response "throwing," for throw, "getting out of the pool" for 
swim, and "he was climbing" for climb. There was a trend for children in the Impaired group to provide a greater proportion of "other verb" responses on past tense probes than the other two groups. These unique kinds of errors found only among the children with autism seem to reflect their primary deficits in pragmatics (cf. Tager-Flusberg, 2000). Thus, it seems likely that the error patterns reported here reflect the difficulty some children with autism have understanding the specific demands of the test instructions, as well as their tendency to perseverate. These findings highlight both the parallels between children with SLI and languageimpaired children with autism with regard to their performance on tense-marking tasks, as well as some qualitative differences in the error patterns. Even some of the omission errors produced by the children with autism may have been for pragmatic reasons, thus not simply reflecting structural deficits in language. Future research should focus on dissecting the linguistic and pragmatic bases of deficits in marking tense among different subgroups of children with autism in order to further refine the phenotypic similarities and differences between autism and SLI.

\section{Relationship between tense marking and repetition of nonsense words}

Research on SLI has highlighted the significance of two clinical markers for this disorder: deficits in tense marking and poor performance on tasks of nonsense word repetition (Bishop et al., 1996; Rice et al., 1995; Rice \& Wexler, 1996; TagerFlusberg \& Cooper, 1999). In this study, we found a significant correlation between performance on each tense marker and nonsense word repetition in the children with autism. Only one study has investigated whether these clinical markers are correlated with one another in children with SLI. Using different versions of the tasks employed in this study, Conti-Ramsden and her colleagues (2001) also found a moderately strong relationship between tense marking (third-person singular and past tense) and nonsense word repetition in a large group of 11-year-old children with a history of SLI. Although discussion about what might underlie the relationships between the phonological and morphosyntactic processes that are measured on these tasks is beyond the scope of this investigation (see Chiat, 2001, for one interpretation), it is significant that similar patterns of deficit on both clinical markers were found for children with SLI and a subgroup of children with autism (see also Botting \& Conti-Ramsden, 2003). Taken together, the findings presented here provide further support for the hypothesis that a subgroup of children with autism may have the same language phenotype that has been reported for children with SLI.

\section{Parallels between autism and SLI}

The evidence presented here and from our previous study (Kjelgaard \& TagerFlusberg, 2001) point to striking parallels between language impaired children with autism and SLI, based on psycholinguistic investigations. Evidence for potential overlap between these populations also comes from behavior genetics studies, particularly studies of the first-degree relatives of both children with autism and children with SLI. A number of studies have found elevated rates of a history of language impairment in the family members of children with autism (Bolton et al., 1994; Folstein et al., 1999; Fombonne, Bolton, Prior, Jordan, \& Rutter, 1997; 
Piven \& Palmer, 1997). Often referred to as part of the "broader autism phenotype," a subgroup of first-degree relatives of children with autism have deficits on a variety of cognitive and language measures compared with control families of children with other forms of mental handicap. These deficits include lower scores on reading and spelling measures, and documented histories of early language delays, language deficits or related cognitive difficulties (Folstein et al., 1999). Thus, families that have at least one child with autism exhibit unusually high rates of language impairment.

One recent study investigated the reverse condition; that is, the presence of autism spectrum disorders among the relatives of children with SLI. In a large population-based sample, Tomblin and his colleagues (Tomblin, Hafeman, \& O'Brien, 2003) examined the siblings of children with SLI and the siblings of age-matched control children for evidence of autistic behavior, as ascertained through parent report using the Autism Behavior Checklist. High rates of autistic behavior were further evaluated using the Autism Diagnostic Interview-Revised (Lord et al., 1994). Several of the siblings met criteria for autism, in contrast to none of the siblings from the control families. Autism was at least 10 times higher in the SLI families than in the general population. Genetic linkage and association studies of both autism and SLI have found evidence of linkage and association in the same region on chromosome 7q (Collaborative Linkage Study of Autism [CLSA], 1999; Fisher, Vargha-Khadem, Watkins, Monaco, \& Pembrey, 1998; International Molecular Genetic Study of Autism Consortium, 1998; O'Brien, Zhang, Nishimura, Tomblin, \& Murray, 2003) and on chromosome 13q (Bartlett et al., 2002; CLSA, 1999, 2001).

A closer look at the tense marker allows for further refinement of the notion of potential overlap between subgroups of autism and SLI. Tense marking is regarded as a specific deficit in SLI in two important ways: the level of children's performance is lower than expected for their level of cognitive development, and children's tense-marking accuracy is less than expected for their general level of language development. This study provides further evidence that tense-marking accuracy is not closely associated with nonverbal intelligence. The correlational analyses revealed that nonverbal intelligence accounted for only $6 \%$ of the variance in performance on third person singular present tense probes and $13 \%$ of the variance in performance on past tense probes. At the individual level, some children with low levels of nonverbal intelligence performed well on the probes, and some children with high levels of nonverbal intelligence performed poorly on the probes.

With regard to the specificity of the tense marker relative to other aspects of language development, Rice (2003) posits a model in which a grammatical marker such as tense marking is characteristic of different forms of language impairment. Of interest here are two possibilities. One form of language impairment with a delayed onset and a slower rate of acquisition is much like that of younger unaffected children. Another form, with a delayed onset and a delay within a delay, suggests that certain elements of the linguistic system, such as tense marking, are selectively delayed in the classic SLI manner. The findings here make it clear that a general language delay is not characteristic of all children with autism, and, as expected, a tense marker would not detect the condition in the Normal subgroup. In contrast, Impaired children with autism perform poorly on the tense marker, but this 
fact alone does not differentiate between a general delay in language acquisition and a delay within a delay. Some suggestion of a specific delay in tense marking is evident in the relatively modest association between lexical performance and tense performance, with only about $29 \%$ of the variance in tense performance accounted for by PPVT performance. Full explication of a possible delay within a delay profile for children with autism will require detailed studies of the children's morphosyntax and related morphological forms. This study is a first step in this direction, and suggests that further investigation is warranted.

This study also contributes to the emerging literature concerning possible clinical markers of language impairments. As Rice (2000) argues, clinical markers provide information that is complementary to that of conventional omnibus language assessments (see also Rice \& Wexler, 2001; Tager-Flusberg \& Cooper, 1999). Clinical markers, such as tense marking and nonword repetition, are very promising as inclusionary criteria for the diagnosis of clinical groups of children with language impairments, especially for studies of etiological factors. Advances in behavioral genetics and identification of behavioral markers for the phenotypes of both autism and specific language impairment might yield better classifications of children with overlapping symptoms of both disorders, because such classifications are likely to be more reflective of common underlying pathology than arbitrary cut-points on conventional tests. The identification of shared clinical markers is a crucial step in our progress toward behavioral phenotypes. It may also be the case that these markers may more strongly predict language impairment if found together in the same individual (Botting \& Conti-Ramsden, 2003).

\section{Caveats}

The evidence from the present sample of autistic children supports the possibility of an SLI subgroup, based on a similarity of symptoms across the two conditions. Symptomatic similarity, although suggestive of similar etiology, is not definitive evidence because similar symptoms can arise for different reasons. For example, omissions of tense marking can appear in second language learners (Paradis \& Crago, 2000) and children with hearing impairments (Norbury, Bishop, \& Briscoe, 2001). In the presence of either of these factors, there would be reason to be cautious in interpreting low performance on tense-marking tasks as a clinical marker of an underlying grammatical deficit of the same sort that is operative in children with SLI or SLI-like subgroups of children with autism.

Despite these concerns, the converging evidence from both psycholinguistic and genetic studies suggest that further research should be conducted that explicitly explores other parallels between language impaired children with autism and SLI. Findings from these investigations will have important implications for refining the ways we diagnose and remediate different subgroups of children with autism spectrum disorders.

\section{ACKNOWLEDGMENTS}

This research was supported by a grant from the NIDCD to the second author (R01DC01803), and NINDS (RO1 NS 38668) and NIDCD (P01 DC 03610, part of the 
Roberts et al.: Tense marking in autism

NICHD/NIDCD Collaborative Programs of Excellence in Autism) grants to the third author. We are extremely grateful to Susan Bacalman, Laura Becker, Karen Condouris, Courtney Hale, Robert Joseph, Margaret Kjelgaard, Echo Meyer, and Jason Smith for their help in collecting some of the data reported in this paper. We offer special thanks to the children and families who participated in this study.

\section{NOTE}

1. These responses are not included in the Rice et al. (1995) data calculations for two reasons. First, in keeping with previous reports in the SLI literature, the calculation of percentage correct is conditional on the use of the target third person singular. Second, in the cross-sectional and longitudinal studies of SLI children ages 5-8 years and control children these responses appear only occasionally. Echolalic responses are even more rare.

\section{REFERENCES}

American Psychiatric Association. (1994). DSM-IV: Diagnostic and statistic manual of mental disorders (4th Ed.). Washington, DC: Author.

Bartlett, C., Flax, J., Logue, M., Vieland, V., Bassett, A., Tallal, P., \& Brzustowicz, L. (2002). A major susceptibility locus for specific language impairment is located on 13q21. American Journal of Human Genetics, 71, 45-55.

Bartolucci, G., Pierce, S. J., \& Streiner, D. (1980). Cross-sectional studies of grammatical morphemes in autistic and mentally retarded children. Journal of Autism and Developmental Disorders, 10, $39-49$.

Bartolucci, G., \& Albers, R. J. (1974). Deictic categories in the language of autistic children. Journal of Autism and Childhood Schizophrenia, 4, 131-141.

Bartolucci, G., \& Pierce, S. (1977). A preliminary comparison of phonological development in autistic, normal, and mentally retarded subjects. British Journal of Disorders of Communication, 12, 137-147.

Bartoclucci, G., Pierce, S., Streiner, D., \& Eppel, P. (1976). Phonological investigation of verbal autistic and mentally retarded subjects. Journal of Autism and Childhood Schizophrenia, 6, 303-315.

Bishop, D. (1992). The underlying nature of specific language impairment. Journal of Child Psychology and Psychiatry, 33, 1-64.

Bishop, D. (2000). Pragmatic language impairment. In D. V. M. Bishop \& L. B. Leonard (Eds.), Speech and language impairments in children: Causes, characteristics, intervention and outcome (pp. 99-113). East Sussex, UK: Psychology Press Ltd.

Bishop, D., Chan, J., Hartley, J., Adams, C., \& Weir, F. (2000). Conversational responsiveness in specific language impairment: Evidence of disproportionate pragmatic difficulties in a subset of children. Development and Psychopathology, 12, 177-199.

Bishop, D., North, T., \& Donlan, C. (1996). Nonword repetition as a behavioural marker for inherited language impairment: Evidence from a twin study. Journal of Child Psychology and Psychiatry, $36,1-13$.

Bishop, D., \& Rosenbloom, L. (1987). Classification of childhood language disorders. In W. Yule \& M. Rutter (Eds.), Language development and disorders: Clinics in developmental medicine. London: MacKeith Press.

Bolton, P., MacDonald, H., Pickles, A., Rios, P., Goode, S., Crowson, M., Bailey, A., \& Rutter, M. (1994). A case-control family history study of autism. Journal of Child Psychology and Psychiatry, 35, 877-900.

Botting, N., \& Conti-Ramsden, G. (2003). Autism, primary pragmatic difficulties, and specific language impairment: Can we distinguish them using psycholinguistic markers? Developmental Medicine and Child Neurology, 45, 515-524. 
Roberts et al.: Tense marking in autism

Chiat, S. (2001). Mapping theories of developmental language impairment: Premises, predictions and evidence. Language and Cognitive Processes, 16, 113-142.

Collaborative Linkage Study of Autism. (1999). An autosomal genomic screen for autism. Collaborative linkage study of autism. American Journal of Medical Genetics, 88, 609-615.

Collaborative Linkage Study of Autism. (2001). Incorporating language phenotypes strengthens evidence of linkage to autism. American Journal of Medical Genetics, 105, 539-547.

Conti-Ramsden, G., Botting, N., \& Faragher, B. (2001). Psycholinguistic markers for specific language impairment (SLI). Journal of Child Psychology and Psychiatry, 42, 741-748.

Conti-Ramsden, G., Crutchley, A., \& Botting, N. (1997). The extent to which psychometric tests differentiate subgroups of children with SLI. Journal of Speech, Language, and Hearing Research, $40,765-777$.

Dollaghan, C., \& Campbell, T. (1998). Nonword repetition and child language impairment. Journal of Speech, Language, and Hearing Research, 41, 1136-1146.

Dunn, L. M., \& Dunn, L. M. (1997). Peabody Picture Vocabulary Test, Third Edition. Circle Pines, MN: American Guidance Service.

Elliott, C. D. (1990). Differential Ability Scales: Introductory and technical handbook. New York: Psychological Corporation.

Fisher, S. E., Vargha-Khadem, F., Watkins, K. E., Monaco, A. P., \& Pembrey, M. E. (1998). Localisation of a gene implicated in a severe speech and language. Nature Genetics, 18, 168-170.

Folstein, S. E., Santangelo, S. L., Gilman, S. E., Piven, J., Landa, R., Lainhart, J., Hein, J., \& Wzorek, M. (1999). Predictors of cognitive test patterns in autism families. Journal of Child Psychology \& Psychiatry \& Allied Disciplines, 40, 1117-1128.

Fombonne, E., Bolton, P. Prior, J., Jordan, H., \& Rutter, M. (1997). A family study of autism: Cognitive patterns and levels in parents and siblings. Journal of Child Psychology and Psychiatry, 38, 667-683.

Gathercole, S., \& Baddeley, A. (1990). Phonological memory deficits in language disordered children: Is there a causal connection? Journal of Memory and Language, 29, 336-360.

Goldman, R., \& Fristoe, M. (1986). Goldman-Fristoe Test of Articulation. Circle Pines, MN: American Guidance Service.

Howlin, P. (1984). The acquisition of grammatical morphemes in autistic children: A critique and replication of the findings of Bartolucci, Pierce, and Streiner, 1980. Journal of Autism and Developmental Disorders, 14, 127-136.

International Molecular Genetic Study of Autism Consortium. (1998). A full genome screen for autism with evidence for linkage to a region on chromosome 7q. Human Molecular Genetics, 7, 571578.

Kjelgaard, M., \& Tager-Flusberg, H. (2001). An investigation of language profiles in autism: Implications for genetic subgroups. Language and Cognitive Processes, 16, 287-308.

Korkman, M., Kirk, U., \& Kemp, S. (1998). NEPSY: A developmental neuropsychological assessment. San Antonio, TX: Psychological Corporation, Harcourt Brace.

Landry, S. H., \& Loveland, K. A. (1989). The effect of social context on the functional communication skills of autistic children. Journal of Autism \& Developmental Disorders, 19, 283-299.

Lee, A., Hobson, R. P., \& Chiat, S. (1994). I, you, me and autism: An experimental study. Journal of Autism and Developmental Disorders, 24, 155-176.

Leonard, L. B. (1989). Language learnability and specific language impairment in children. Applied Psychlinguistics, 10, 179-202.

Leonard, L. B., Bortolini, U., Caselli, M. C., McGregor, K. K., \& Sabbadini, L. (1992). Morphological deficits in children with specific language impairment. The status of features in the underlying grammar. Language Acquisition, 2, 151-179.

Lord, C., \& Paul, R. (1997). Language and communication in autism. In D. J. Cohen \& P. R. Volkmar (Eds.), Handbook of autism and pervasive developmental disorders (2nd ed., pp. 195-225). New York: Wiley.

Lord, C., Risi, S., Lambrecht, L., Cook, E. H., Jr., Leventhal, B.L., DiLavore, P.C., Pickles, A., \& Rutter, M. (2000). The autism diagnostic observation schedule-generic: A standard measure of social and communication deficits associated with the spectrum of autism. Journal of Autism \& Developmental Disorders, 30, 205-223.

Lord, C., Rutter, M., \& LeCouteur, A. (1994). Autism Diagnostic Interview-Revised: A revised version of a diagnostic interview for caregivers of individuals with possible pervasive developmental disorders. Journal of Autism and Developmental Disorders, 24, 659-668. 
Roberts et al.: Tense marking in autism

Loveland, K., McEvoy, R., Tunali, B., \& Kelley, M. L. (1990). Narrative story telling in autism and Down's syndrome. British Journal of Developmental Psychology, 8, 9-23.

Norbury, C. F., Bishop, D. V. M., \& Briscoe, J. (2001). Production of English finite verb morphology: A comparison of SLI and mild-moderate hearing impairment. Journal of Speech, Language, and Hearing Research, 44, 165-178.

O’Brien, E., Zhang, X., Nishimura, C., Tomblin, J. B., \& Murray, J. (2003). Association of specific language impairment (SLI) to the region of 7q31. American Journal of Human Genetics, 72, 1536-1543.

Paradis, J., \& Crago, M. (2000). Tense and temporality: A comparison between children learning a second language and children with SLI. Journal of Speech, Language, and Hearing Research, 43, 834-847.

Pierce, S., \& Bartolucci, G. (1977). A syntactic investigation of verbal autistic, mentally retarded and normal children. Journal of Autism and Childhood Schizophrenia, 7, 121-134.

Piven, J., \& Palmer, P. (1997). Cognitive deficits in parents from multiple incidence autism families. Journal of Child Psychology and Psychiatry, 38, 1011-1021.

Rapin, I. (Ed.). (1996). Preschool children with inadequate communication. London: MacKeith Press.

Rapin, I., \& Allen, D. (1983). Developmental language dirsorders: A clinical update. Journal of Child Psychology and Psychiatry, 37, 643-655.

Rice, M. L. (2000). Grammatical symptoms of specific language impairment. In D. V. M. Bishop \& L. B. Leonard (Eds.), Speech and language impairments in children (pp. 17-34). East Sussex, UK: Psychology Press.

Rice, M. L. (2003). A unified model of specific and general language delay: Grammatical tense as a clinical marker of unexpected variation. In Y. Levy \& J. Schaeffer (Eds.), Language competence across populations: Towards a definition of specific language impairment in children (pp. 6394). Mahwah, NJ: Erlbaum.

Rice, M. L., \& Wexler, K. (1996). Toward tense as a clinical marker of specific language impairment in English-speaking children. Journal of Speech and Hearing Research, 39, 239-257.

Rice, M. L., \& Wexler, K. (2001). Test of early grammatical impairment. San Antonio, TX: Psychological Corporation.

Rice, M. L., Wexler, K., \& Cleave, P. L. (1995). Specific language impairment as a period of extended optional infinitive. Journal of Speech and Hearing Research, 38, 850-863.

Rice, M. L., Wexler, K., \& Hershberger, S. (1998). Tense over time: The longitudinal course of tense acquisition in children with specific language impairment. Journal of Speech and Hearing Research, 41, 1412-1431.

Rice, M. L., Wexler, K., Marquis, J., \& Hershberger, S. (2000). Acquisition of irregular past tense by children with specific language impairment. Journal of Speech, Language, \& Hearing Research, 43, 1126-1145.

Stark, R.E., \& Tallal, P. (1981). Selection of children with specific language deficits. Journal of Speech and Hearing Disorders, 46, 114-122.

Stone, W., \& Caro-Martinez, L. M. (1990). Naturalistic observations of spontaneous communication in autistic children. Journal of Autism and Developmental Disorders, 20, 437-454.

Tager-Flusberg, H. (1989). A psycholinguistic perspective on language development in the autistic child. In G. Dawson (Ed.), Autism: New directions in diagnosis, nature and treatment (pp. 92-115). New York: Guilford Press.

Tager-Flusberg, H. (1994). Dissociations in form and function in the acquisition of language by autistic children. In H. Tager-Flusberg (Ed.), Constraints on language acquisition: Studies of atypical children (pp. 175-194). Hillsdale, NJ: Erlbaum.

Tager-Flusberg, H. (1997). The role of theory of mind in language acquisition: Contributions from the study of autism. In L. Adamson \& M. A. Romski (Eds.), Communication and language acquisition: Discoveries from atypical development (pp. 133-158). Baltimore, MD: Paul Brookes.

Tager-Flusberg, H. (1999). A psychological approach to understanding the social and language impairments in autism. International Review of Psychiatry, 11, 325-334.

Tager-Flusberg, H. (2000). The challenge of studying language development in autism. In L. Menn \& N. Bernstein Ratner (Eds.), Methods for studying language production (pp. 313-332). Mahwah, NJ: Erlbaum.

Tager-Flusberg, H., \& Anderson, M. (1991). The development of contingent discourse ability in autistic children. Journal of Child Psychology and Psychiatry, 32, 1123-1134. 
Roberts et al.: Tense marking in autism

Tager-Flusberg, H., \& Calkins, S. (1990). Does imitation facilitate the acquisition of grammar? Evidence from a study of autistic, Down syndrome and normal children. Journal of Child Language, $17,591-606$.

Tager-Flusberg, H., Calkins, S., Nolin, T., Baumberger, T., Anderson, M., \& Chadwick-Dias, A. (1990). A longitudinal study of language acquisition in autistic and Downs syndrome children. Journal of Autism and Developmental Disorders, 20, 1-21.

Tager-Flusberg, H., \& Cooper, J. (1999). Present and future possibilities for defining a phenotype for specific language impairment. Journal of Speech, Language, and Hearing Research, 42, $1275-1278$.

Tomblin, J. B., Hafeman, L., \& O'Brien, M. (2003). Autism and autism risk in siblings of children with specific language impairment. International Journal of Language and Communication Disorders, 38, 235-250.

Tomblin, J. B., \& Zhang, X. (1999). Language patterns and etiology in children with specific language impairment. In H. Tager-Flusberg (Ed.), Neurodevelopmental disorders (pp. 361-382). Cambridge, MA: MIT Press/Bradford Books.

Wetherby, A., Prizant, B., \& Hutchinson, T. (1998). Communicative, social/affective, and symbolic profiles of young children with autism and pervasive developmental disorders. American Journal of Speech Language Pathology, 7, 79-91.

Wetherby, A., \& Prutting, C. (1984). Profiles of communicative and cognitive-social abilities in autistic children. Journal of Speech and Hearing Research, 27, 364-377. 